\title{
УМОВИ СИНХРОНІЗМУ ЧЕРЕНКОВСЬКОГО ТИПУ ДЛЯ КОНІЧНОї ЕМІСІї ФЕМТОСЕКУНДНИХ БЕССЕЛІВСЬКИХ ПУЧКІВ
}

\author{
І.В. БЛОНСЬКИЙ, В.М. КАДАН
}

УДК 535.3; 535.5; 534-16

Інститут фізики НАН України

(C) 2011

(46, Просn. Науки, Kиїв 03650; e-mail: blon@iop. kiev. ua)

Показано, що кутовий розподіл довжини хвилі конічної емісії фемтосекундного бесселівського пучка у воді визначається умовою рівності осьових фазових швидкостей всіх її спектральних компонент. Підсилення в осьовому напрямку внаслідок чотирихвильового змішування приводить до появи дискретних кілець конічної емісії.

\section{1. Вступ}

Майже відразу після введення у практику наукових досліджень імпульсних лазерних джерел в Інституті фізики НАН України під керівництвом М.С. Бродина були започатковані та отримали активний розвиток дослідження ефектів самовпливу лазерного випромінювання в твердотільних керрівських середовищах. У напівпровідникових матеріалах з різною структурою електронних зон було встановлено основні механізми, які визначають: ефекти самофокусування та дефокусування лазерного випромінювання, конкуренцію процесів самофокусування та багатофотонного поглинання випромінювання, величину та швидкодію нелінійно-оптичного відгуку напівпровідників та інші процеси (див., наприклад, [1, 2]). Такі дослідження набули якісно нового розвитку в останні роки у зв'язку з введенням у дію при Інституті фізики НАН України "лазерного фемтосекундного комплексу", у створенні якого значну роль відіграв М.С. Бродин.

$\mathrm{У}$ цій роботі мова йде про дослідження природи нових нелінійно-оптичних явищ, які супроводжують поширення потужних фемтосекундних лазерних імпульсів у керрівських середовищах. Одним із таких явищ є так звана конічна емісія (KE), яка утворюється, зокрема, при спонтанній філаментації гауссів- ського пучка у прозорих керрівських середовищах. Характерною ознакою такої KЕ є наростання частоти випромінювання зі збільшенням кута $\theta$. Зі збільшенням довжини філамента початково неперервний частотно-кутовий розподіл КЕ розбивається на низку дискретних кілець з фіксованими кутами $\theta$ і своєю власною частотою випромінювання для кожного 3 них.

\section{2. Моделі конічної емісії}

Оскільки центральну роль у розумінні подальшого відіграють конічні хвилі, то зупинімось коротко на ï основних властивостях. Лінійна монохроматична конічна хвиля є сукупністю плоских хвиль, хвильові вектори яких $\mathbf{k}$ розподілені по поверхні конуса під кутом $\theta$ до осі. Розподіл інтенсивності конічної хвилі, подібно до філамента, у поперечному перерізі має інтенсивний осьовий максимум незмінного діаметра уздовж осі, оточений концентричними кільцями зростаючого діаметра, і описується квадратом функції Бесселя. Тому конічні хвилі називаються також бесселівськими. На практиці конічна хвиля найчастіше створюється шляхом фокусування гауссівського пучка за допомогою аксикона (рис. 1). Осьова фазова швидкість їі поширення в дисперсійному середовищі $V=c /(n \cos \theta)$ перевищує світлову швидкість $c / n$ для даної довжини хвилі [3]. Якщо амплітудний фронт конічної хвилі не має нахилу відносно фазового фронту, то її осьова групова швидкість $v$ (швидкість переміщення осьового максимуму світлового імпульсу) дорівнює $v=v_{m} / \cos \theta$, де $v_{m}$ - групова швидкість світла у середовищі. Однак відмінність групової і фазової швидкостей у матеріалі фокусуючого аксикона 


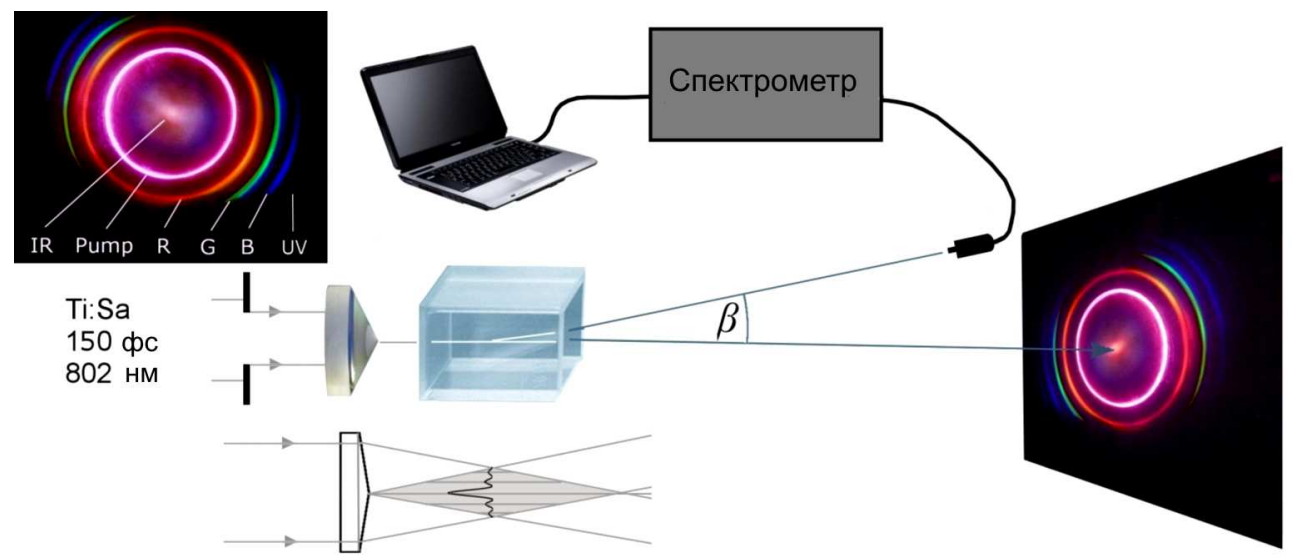

Рис. 1. Схема експерименту і фотографія КЕ на екрані на відстані 500 см від аксікона при повністю відкритій діафрагмі і енергії

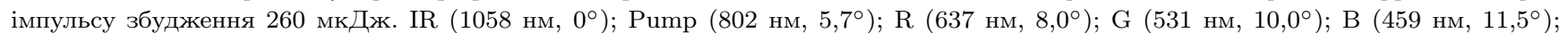
UV $(390$ нм, 12,9$)$. В нижній частині рисунка схематично показана бесселівська зона, сформована аксіконом, 3 відповідним розподілом інтенсивності

створює нахил $\alpha$ амплітудного хвильового фронту, і вираз для групової швидкості конічної хвилі збудження $v_{0}$ набуває вигляду $v_{0}=v_{m} \cos \alpha / \cos \left(\theta_{0}+\alpha\right)$ [4].

В основі більшості сучасних моделей утворення KЕ (трихвилеве змішування (ТХ3) [5], фазова самомодуляція [6-8], утворення так званих $X$-хвиль [9-11]) лежить уявлення про точкове широкосмугове джерело, яке рухається разом з імпульсом в області високого градієнта інтенсивності поля, де, власне, і відбувається розширення спектра, в першу чергу, внаслідок фазової самомодуляції. Це випромінювання при суперпозиції і дає частотно-кутовий розподіл для КЕ, в якому кут збільшується зі збільшенням зсуву в антистоксову область. Інтерференційна модель [8] враховує інтерференцію КЕ від декількох осьових максимумів вздовж філамента, яка приводить до розщеплення безперервного за кутом спектра KE на дискретні кільця. Запропоновані також моделі чотирихвильового змішування (ЧХЗ) [12-14], черенковського випромінювання (ЧВ) на динамічній межі антихвилевода, створюваного при філаментації [15, 16]. У роботі [16] знайдено, що для КЕ у повітрі добуток $n \cos \theta$ є однаковим для всіх компонент KЕ. Це означає рівність осьової фазової швидкості для всіх компонент KЕ. Водночас центральну роль у моделюванні нелінійного утворення $X$-хвиль відіграє припущення про рівність осьових групових швидкостей всіх компонент поліхроматичного конічного хвильового пакета, що приводить до високих інтенсивностей нелінійних процесів [17].

Експериментальну перевірку відповідності кутового спектра КЕ філаментів у повітрі моделям ЧХЗ [14],
$X$-хвиль [11] і ЧВ [16] здійснено в [18]. Показано, що вираз для кутового спектра КЕ в моделі ЧВ може розглядатися як окремий випадок більш загального виразу в моделі $X$-хвиль, якщо групова швидкість філамента дорівнює фазовій швидкості на частоті збудження. Саме в такому випадку досягнуто найкраще узгодження теоретичних розрахунків з експериментом.

Проте в зазначених вище експериментах KЕ досліджували у філаментованому режимі. Внаслідок великої нелінійної зміни показника заломлення на осі філамента виникає необхідність використання підгоночних параметрів при порівнянні теоретичних і експериментальних результатів. У даній роботі нами використано режим слабонелінійного збудження бесселівською хвилею. Саме режим слабкої нелінійності до переходу в сильно нелінійний режим філаментації дозволить, на нашу думку, домогтися кількісного опису кутового спектра KE $з$ перших принципів без використання підгоночних параметрів, оскільки складність такого опису суттєво пов'язана з неоднозначністю просторово-часових параметрів електромагнітного поля, зокрема осьових групової і фазової швидкостей, в сильно нелінійному режимі філаментації. Ще одна перевага бесселівського збудження полягає в можливості поширити виміряну кутову залежність КЕ також і на осьовий напрямок $(\theta=0)$ в інфрачервону область спектра. 3 іншого боку, наведені в $[14,11,16]$ аналітичні вирази для кутових спектрів KЕ не можуть бути прямо застосовані для випадку бесселівського збудження, тому пряма перевірка висновків цих робіт неможли- 
ва. У зв'язку з цим у даній роботі ми поставили за мету з'ясувати який принцип синхронізму, груповий чи фазовий, діє при генерації KE, використовуючи у ролі керрівського середовища воду, де групова і фазова швидкості суттєво відрізняються. У роботі однозначно показано, що при використаних нами експериментальних умовах кутова дисперсія КЕ описується залежністю черенковського типу, яка витікає з умови рівності осьових фазових швидкостей всіх компонент поліхроматичного конічного хвильового пакета. Дискретність кілець пояснюється наявністю виділеного напрямку вздовж осі пучка накачки, в якому здійснюється стимулювання процесу ЧX3.

\section{3. Експериментальні результати i обговорення}

Для збудження KЕ нами використано горизонтально поляризовані фемтосекундні лазерні імпульси на довжині хвилі 802 нм, тривалістю по половинному рівню $\tau=150$ фс, з частотою повторення 1 кГц і спектральною шириною 10 нм (рис. 1). Пучок додатково обмежувався регульованою діафрагмою з максимальним діаметром отвору 12 мм і фокусувався аксиконом зі скла К8 діаметром 12 мм з кутом біля основи 11, $2^{\circ}$ в скляну кювету з водою довжиною 30 мм так, щоб максимум осьової інтенсивності в бесселівській зоні припадав на середину кювети. Кут сформованої аксиконом конічної хвилі відносно осі у воді $\theta_{0}=4,3^{\circ}$. Як видно з рис. 1, КЕ характеризується вузькими дискретними кільцями червоного $(\mathrm{R})$, зеленого $(\mathrm{G})$ і синього (В) кольору та слабким ультрафіолетовим (UV) кільцем. В осьовому ж напрямку генерується вузький пучок (ширина по половинному рівню $2^{\circ}$ ) IЧ-випромінювання (IR). Крім того, реєструється конічне випромінювання накачки (Pump). За допомогою гнучкого кварцового світловоду діаметром 1 мм на відстані 50 см від аксикона здійснено зондування KE в максимумах інтенсивності кілець під різними кутами $\beta$, а зібране світло проектувалося на вхідну щілину спектрометра.

Поляризація КЕ і осьового ІЧ-випромінювання збігається $з$ поляризацією випромінювання накачки. Інтенсивність KЕ має порогову (185 мкДж) і надлінійну залежність від енергії імпульсу збудження, що вказує на їі стимульований характер. При збільшенні енергії імпульсу збудження спочатку одночасно виникають червоне кільце і ІЧ-випромінювання, а потім послідовно з'являються кільця - зелене, синє і ультрафіолетове. Найбільш різкими і монохромати-

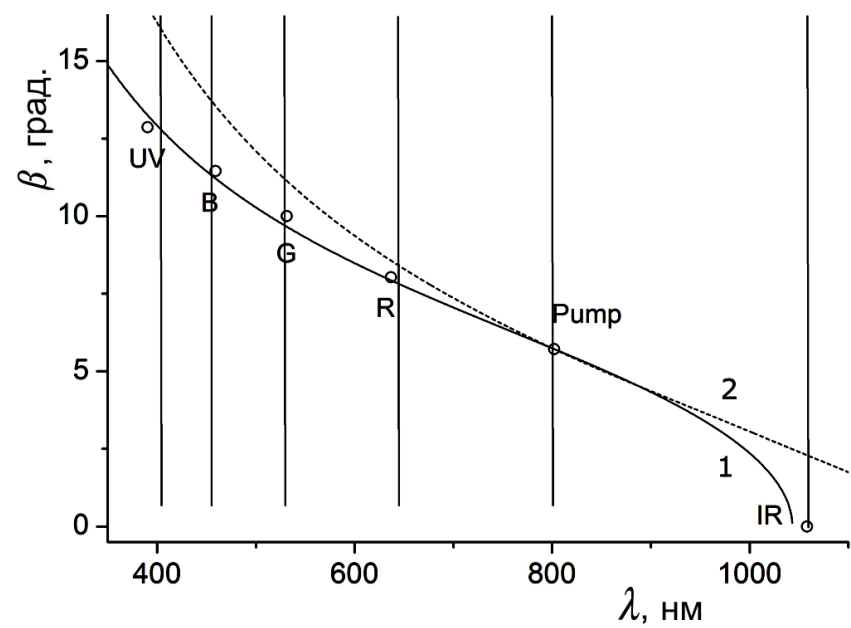

Рис. 2. Кутова залежність спектра KЕ для синхронізму черенковського типу. Світлими кружечками показано експериментальні точки. Суцільна лінія 1 - фазовий синхронізм; штрихова 2 - груповий

чними вони є при мінімальному рівні збудження. При збільшенні енергії імпульсу збудження структура кілець ускладнюється і в осьовому напрямку з'являється випромінювання квазібілого суперконтинууму, очевидно, внаслідок переходу до сильно нелінійного режиму філаментації в бесселівському пучку. Тому надалі ми обмежуємося обговоренням KЕ при мінімальному рівні збудження.

На рис. 2 кружечками показано енергії квантів і кути локалізації кілець різного порядку при енергії імпульсу збудження 260 мкДж. Показано також точки "Рump" та "IR". Спектральні ширини смуг КЕ в межах кільця близькі до 30 меВ і дещо перевищують ширину смуги накачки (20 меВ).

Ці експериментальні дані порівнюються з розрахунковими кутовими спектрами КЕ при виконанні умов синхронізму двох типів - фазового (суцільна лінія) і групового (штрихова). У першому випадку вважалося, що фаза всіх компонент поліхроматичного конічного хвильового пакета однакова на осі пучка, тобто осьові фазові швидкості у воді $V=$ $c /(n \cos \theta)$ однакові для всіх довжин хвиль і дорівнюють фазовій швидкості конічної хвилі збудження $V_{0}=c /\left(n_{0} \cos \theta_{0}\right)=2,2627 \cdot 10^{10} \mathrm{~cm} / \mathrm{c}$. У другому випадку вважалося, що осьові групові швидкості у воді $v=v_{m} / \cos \theta$ однакові для всіх довжин хвиль і дорівнюють груповій швидкості конічної хвилі збудження $v_{0}=v_{m} \cos \alpha / \cos \left(\theta_{0}+\alpha\right)=2,2391 \cdot 10^{10} \mathrm{~cm} /$ с. За нашими розрахунками для матеріалу аксикона К8 нахил амплітудного хвильового фронту відносно фазового $\alpha=0,15^{\circ}$ у воді, а для всіх частот KЕ крім збуджую- 
чої він дорівнював нулю. Кути $\theta$ у воді перераховані в кути $\beta$ в повітрі. На відміну від [18] не використовували аналітичні вирази для залежності кута KE від довжини хвилі, а задача була розв'язана чисельно $з$ використанням дисперсії показника заломлення води за результатами роботи [19]. Зауважимо, що для заряду, швидкість якого $V_{c}$ перевищує світлову, кутова залежність довжини хвилі черенковського випромінювання в дисперсійному середовищі виникає як наслідок аналогічної умови черенковського синхронізму: $V_{c}=c /(n \cos \theta)$.

3 наведеного графіка видно, що експериментальні точки, включаючи і осьове ІЧ-випромінювання, добре описуються черенковською кутовою залежністю 1 для фазового синхронізму. Цей результат підтверджує висновок робіт $[16,18]$ про рівність осьових фазових швидкостей всіх компонент КЕ філамента у повітрі і поширює його, по-перше, на конденсовані середовища (воду), а по-друге - на випадок збудження бесселівською хвилею. Для осьового випромінювання умова фазового синхронізму набуває особливо простого вигляду $V_{0}=c / n_{\mathrm{IR}}$.

Зазначимо, що умова черенковського синхронізму не обов'язково передбачає саме черенковський механізм випромінювання, тобто поляризацію середовища рухомим зарядом. Хоча у нашому експерименті дійсно можливе поздовжне розділення зарядів у плазмовому сліді, яке може служити джерелом KЕ. Зокрема, з позицій такого механізму пояснювалася генерація терагерцового випромінювання в фемтосекундних філаментах [20]. Однак, по-перше, диполь не може випромінювати в осьовому напрямку, а по-друге, з міркувань симетрії, поляризація генерованої ним КЕ повинна бути радіальною. Оскільки спостережуване випромінювання є плоскополяризованим, а його ІЧкомпонента спрямована вздовж осі, власне черенковський механізм KЕ слід з розгляду виключити.

Проте умова фазового синхронізму черенковського типу описує неперервний кутовий спектр KE і не дає відповіді про природу спостереженої дискретності кілець. Звернімося у цьому зв'язку до явища ЧХЗ, якому сприяє конфігурація бесселівських пучків внаслідок високої інтенсивності осьового максимуму ( 50 ТВт/см² при енергії імпульсу 300 мкДж) і великої довжини центрального піка. Тому можна припустити, що випромінювання IR i R можуть генеруватися у процесі ЧХЗ двома квантами накачки. Дійсно, на рис. 2 вертикальними лініями позначено довжини хвиль, які відповідають комбінаційним довжинам хвиль за схемою ЧХЗ: $1 / \lambda_{R}=2 / \lambda_{0}-1 / \lambda_{\mathrm{IR}}$; а для більш високих порядків згідно з умовами $1 / \lambda_{\mathrm{G}}=2 / \lambda_{\mathrm{R}}-1 / \lambda_{0}$;
$1 / \lambda_{\mathrm{B}}=2 / \lambda_{\mathrm{G}}-1 / \lambda_{\mathrm{R}}$ і $1 / \lambda_{\mathrm{UV}}=2 / \lambda_{\mathrm{B}}-1 / \lambda_{\mathrm{G}}$. Як можна бачити, виміряні довжини хвиль ліній $\mathrm{R}, \mathrm{G}, \mathrm{B}$ i UV добре узгоджуються з очікуваними при ЧХЗ. Крім цього, специфіка ЧХЗ в конічному пучку приводить і до зміни звичайних умов фазового синхронізму: $2 \mathbf{k}_{0}=\mathbf{k}_{\mathrm{IR}}+\mathbf{k}_{\mathrm{R}}$. Внаслідок того, що густина інтенсивності бесселівського пучка на осьовому максимумі перевищує таку в першому кільці в 6,25 раза, генерація нових компонент, яка пропорційна квадрату інтенсивності накачки, поблизу порога буде відбуватися виключно локально на осі пучка. У такому випадку втрачають сенс звичайні умови фазового синхронізму для ЧХЗ, а важливо лише щоб сума осьових фазових швидкостей конічних хвиль, які генеруються, дорівнювала подвоєній фазовій швидкості конічної хвилі накачки: $V_{\mathrm{IR}}+V_{\mathrm{R}}=2 V_{0}$ або $c /\left(n_{\mathrm{IR}} \cos \theta_{\mathrm{IR}}\right)+c /\left(n_{\mathrm{R}} \cos \theta_{\mathrm{R}}\right)=2 c /\left(n_{0} \cos \theta_{0}\right)$. Ця умова еквівалентна умові поздовжнього фазового синхронізму [21] i, безумовно, виконується на кривій 1 , де всі фазові швидкості однакові.

Із зазначеного стає зрозумілою і причина дискретності кілець КЕ. У вказаній геометрії експерименту існує єдиний виділений напрямок - осьовий, у якому найбільше стимулюється випромінювання у процесі ЧХ3. Саме тому з континууму можливих кутів KE $\theta$ реалізується єдиний варіант $\theta=0$, в якому генерується інфрачервоне випромінювання, що задовольняє умову $V_{0}=c / n_{\mathrm{IR}}$. Спектральний склад інших кілець визначається у вигляді комбінаційних довжин хвиль при ЧХ3: $1 / \lambda_{\mathrm{R}}=2 / \lambda_{0}-1 / \lambda_{\mathrm{IR}}$ та ін. Як бачимо, точки перетину кривої 1 з вертикальними лініями комбінаційних довжин хвиль ЧХЗ, близькі до експериментально спостережуваних. Зауважимо, що у даному розгляді ЧХЗ не визначає умови синхронізму KE, a $є$ лише вторинним явищем, створюючи селективні умови для генерації дискретних частот.

Щодо умови групового синхронізму, необхідного для максимальної ефективності генерації KE, то їі виконання також можливе за умови належного підбору коректуючого параметра $\alpha$, тобто нові генеровані хвилі KЕ матимуть необхідний нахил амплітудного хвилевого фронту. Проте це питання ми резервуємо для подальших досліджень.

\section{4. Висновки}

Таким чином, у роботі показано, що в умовах даного експерименту кутовий спектр KЕ визначається умовою рівності осьових фазових швидкостей всіх ㄲ̈ компонент. Дискретність кілець КЕ пояснюється наявністю виділеного осьового напрямку пучка накачки, 
вздовж якого відбувається генерація і посилення ІЧвипромінювання у процесі ЧХЗ з одночасною генерацією червоного випромінювання та решти частот у процесах ЧХЗ більш високих порядків.

Роботу виконано за часткової підтримки ДФФД України (проект Ф40.2/067). Автори висловлюють щиру вдячність співробітникам ЦКПП "Лазерний фемтосекундний комплекс" I.M. Дмитруку і П.І. Коренюку за надану допомогу в дослідженнях та проф. В.П. Кандідову (МДУ) за обговорення та корисні зауваження до рукопису статті.

1. M.S. Brodin and A.A. Borshch, Refractive Nonlinearity of Wide-Band Semiconductors and Applications (Harwood Academic Publishers, London, 1990).

2. А.О. Борщ, М.С. Бродин, В.Я. Резніченко та ін., Iнститут фізики НАН Украӥни. 80 років (Евросвіт, Львів, 2009).

3. P. Saari, Ultrafast Photonics (Institute of Physics Publishing, Bristol and Philadelphia, 2004).

4. A. Couairon, P. Di Trapani, and D. Faccio, Conical Waves, Filaments and Nonlinear Filamentation Optics (Aracne, Rome, 2007).

5. M. Kolesik, E.M. Wright, and J.V. Moloney, Opt. Express 13, 10729 (2005).

6. O.G. Kosareva, V.P. Kandidov, A. Brodeur et al., Opt. Lett. 22, 1332 (1997).

7. A.E. Dormidonov, V.P. Kandidov, V.O. Kompanets et al., JETP Lett. 91, 373 (2010).

8. V.P. Kandidov, O.G. Kosareva, I.S. Golubtsov et al., Appl. Phys. B 77, 149 (2003).

9. P. Di Trapani, G. Valiulis, A. Piskarskas et al., Phys. Rev. Lett. 91, 093904 (2003).

10. D. Faccio, M.A. Porras, A. Dubietis et al., Phys. Rev. Lett. 96, 193901 (2006).

11. D. Faccio, A. Averchi, A. Lotti et al., Opt. Express 16, 1565 (2008).

12. D.J. Harter and R.W. Boyd, Opt. Lett. 7, 491 (1982).

13. Q. Xing, K.M. Yoo, and R.R. Alfano, Appl. Opt. 32, 2087 (1993).

14. G. Luther, A. Newell, J. Moloney, and E. Wright, Opt. Lett. 19, 789 (1994).
15. I. Golub, Opt. Lett. 15, 305 (1990).

16. E.T.J. Nibbering, P.F. Curley, G. Grillon et al., Opt. Lett. 21, 62 (1996).

17. D. Faccio, P. Di Trapani, Laser Phys. 18, 253 (2008).

18. P. Maioli, R. Salame, N. Laskoux et al., Opt. Express 17, 4726 (2009).

19. M. Daimon and A. Masumura, Appl. Opt. 46, 3811 (2007).

20. C.D. Amico, A. Houard, S. Akturk et al., New J. Phys. 10, 013015 (2008).

21. A. Dubietis, P. Polesana, G. Valiulis et al., Opt. Express 15, 4168 (2007).

Одержано 05.07.11

УСЛОВИЯ СИНХРОНИЗМА ЧЕРЕНКОВСКОГО ТИПА ДЛЯ КОНИЧЕСКОЙ ЭМИССИИ ФЕМТОСЕКУНДНЫХ БЕССЕЛЕВСКИХ ПУЧКОВ

И.В. Блонский, В.Н. Кадан

$\mathrm{P}$ е $з$ ю м е

Показано, что угловое распределение длины волны конической эмиссии фемтосекундного бесселевского пучка в воде определяется условием равенства осевых фазовых скоростей всех ее спектральних компонент. Усиление в осевом направлении, вызванное процессом четырехволнового смешивания, приводит к появлению дискретных колец конической эмиссии.

\section{CHERENKOV-TYPE CONDITIONS OF SYNCHRONISM} FOR CONICAL EMISSION OF FEMTOSECOND BESSEL BEAMS

\section{V. Blonsky, V.M. Kadan}

Institute of Physics, Nat. Acad. of Sci. of Ukraine (46, Nauka Ave., Kyiv 03650, Ukraine;

e-mail: blon@iop.kiev.ua)

$\mathrm{S} u \mathrm{~mm}$ a r y

It has been demonstrated that the angular distribution of wavelengths in the conical emission (CE) by a femtosecond Bessel beam in water is governed by the condition that the axial phase velocities of all CE spectral components are identical. The enhancement along the axial direction owing to the four-wave mixing results in the appearance of discrete rings of conical emission. 